\title{
Electronic Cigarette Use among Mississippi Adults, 2015
}

\author{
Vincent L. Mendy, ${ }^{1,2}$ Rodolfo Vargas, ${ }^{1}$ Gerri Cannon-Smith, ${ }^{1}$ Marinelle Payton, ${ }^{2,3}$ \\ Enkhmaa Byambaa, ${ }^{4}$ and Lei Zhang ${ }^{1}$ \\ ${ }^{1}$ Office of Health Data and Research, Mississippi State Department of Health, Jackson, MS, USA \\ ${ }^{2}$ Department of Epidemiology and Biostatistics, School of Public Health, Jackson State University, Jackson, MS, USA \\ ${ }^{3}$ Center of Excellence in Minority Health and Health Disparities, Institute of Epidemiology and Health Services Research, \\ School of Public Health, Jackson State University, Jackson, MS, USA \\ ${ }^{4}$ Department of Internal Medicine, University of California Davis, School of Medicine, Sacramento, CA, USA
}

Correspondence should be addressed to Vincent L. Mendy; vincent.l.mendy@jsums.edu

Received 5 May 2017; Accepted 9 July 2017; Published 16 August 2017

Academic Editor: Hua Yong

Copyright (C) 2017 Vincent L. Mendy et al. This is an open access article distributed under the Creative Commons Attribution License, which permits unrestricted use, distribution, and reproduction in any medium, provided the original work is properly cited.

\begin{abstract}
Electronic cigarettes (e-cigarettes) are battery-powered devices that deliver nicotine in the form of aerosol. We identify differences and associations in e-cigarette use by sociodemographic characteristics and describe the reported reasons for initiating use among Mississippi adults. We used the 2015 Mississippi Behavioral Risk Factor Surveillance System, which collected information on e-cigarette use from 6,035 respondents. The prevalence of current e-cigarette use and having ever tried an e-cigarette was determined overall and by sociodemographic characteristics. Weighted prevalences and $95 \%$ confidence intervals were calculated, and prevalences for subgroups were compared using the $X^{2}$ tests and associations were assessed using logistic regression. In 2015, $4.7 \%$ of Mississippi adults currently used e-cigarettes, while $20.5 \%$ had ever tried an e-cigarette. The prevalence of current e-cigarette use was significantly higher for young adults, whites, men, individuals unable to work, those with income $\$ 35,000-\$ 49,999$, and current smokers compared to their counterparts. Similar results were observed for having ever tried an e-cigarette. E-cigarette use was associated with age, race, income, and smoking status. Most (71.2\%) of current e-cigarette users and over half (52.1\%) of those who have ever tried e-cigarettes reported that a main reason for trying or using e-cigarettes was "to cut down or quit smoking."
\end{abstract}

\section{Introduction}

Electronic cigarettes (e-cigarettes) are battery-powered devices that provide inhaled doses of nicotine by delivering a vaporized propylene glycol/nicotine mixture [1]. Carcinogens and toxins have been found in the aerosol of some e-cigarettes $[2,3]$. E-cigarettes represent a major change in the tobacco control landscape [3]. They have been marketed as both a substitute for conventional cigarettes and a smoking cessation option by E-Cigarettes Companies [4, 5]; however, there is limited evidence that e-cigarette use promotes long-term smoking cessation [3, 6-9]. The Food and Drug Administration (FDA) recently finalized a rule extending its regulatory authority to all tobacco products, including e-cigarettes [2].
Recent evidence suggests that there has been an increase in the prevalence of e-cigarette use among adults in the United States (US) [10]. In Utah, for example, the use of e-cigarettes has increased fivefold in recent years, from $1.9 \%$ in 2011 to $10.5 \%$ in 2015 [11]. Given this trend, public health professionals are concerned that e-cigarette use could encourage smoking initiation, long-term dual use among current smokers, the reinitiation of smoking among former smokers, and the maintenance of nicotine addiction $[2,10]$. In Mississippi, although the overall prevalence of current conventional cigarette use decreased relatively by $11.5 \%$ between $2011(26.0 \%)$ and 2015 (23.0\%), [12] the state still has one of the highest prevalences of current conventional smoking, and the prevalence is higher for some sociodemographic subgroups than for others [12]. Data on e-cigarette use 
among Mississippi adults are limited. In 2015, the Mississippi Behavioral Risk Factor Surveillance System (BRFSS) assessed e-cigarette use for the first time. We assess differences in ecigarette use by sociodemographic characteristics, examine the association between e-cigarette use and sociodemographic characteristics and smoking status, and describe the reasons given for initiating use by select demographic characteristics among Mississippi adults.

\section{Materials and Methods}

2.1. Data Source. We analyzed data from the 2015 Mississippi Behavioral Risk Factors Surveillance System (BRFSS), which included an optional module on e-cigarette use. The BRFSS is a state-based, random-digit-dialed telephone survey of the US noninstitutionalized civilian population aged 18 years or older. The survey is conducted in all 50 states, the District of Columbia, and three US territories (Puerto Rico, Guam, and the US Virgin Islands). Data from the BRFSS have been shown to reliably and validly assess health risk factors [13]. Beginning in 2011, BRFSS data included both landline and cell phone surveys and a new weighting methodology was used to improve accuracy of the data [14]. The BRFSS study has been approved by the human research review board at each state's department of health. Detailed information about BRFSS is available at https://www.cdc.gov/brfss/. This study was deemed exempt by the Mississippi State Department of Health Institutional Review Board.

2.2. E-Cigarette Use. E-cigarette use was determined by first describing an e-cigarette for the respondent ("The next questions are about electronic cigarettes, also known as ecigarettes, vaping devices, or hookah pens. E-cigarettes look like regular cigarettes, but are battery-powered and produce vapor instead of smoke. E-cigarettes can be bought as onetime, disposable products, or can be bought as reusable kits with a cartridge. These cartridges come in many different flavors and nicotine concentrations. Using e-cigarettes is also called "vaping."). Respondents were then asked "Have you ever tried an e-cigarette, even just one time in your entire life?" Those who answered "yes" were classified as having "ever tried an e-cigarette." These respondents were then asked "Do you now smoke e-cigarettes every day, some days, or not at all?" Respondents who reported using e-cigarettes every day or some days were classified as current e-cigarette users. Respondents were then asked "What best describes your reason for using or trying e-cigarettes?" Possible responses were 1: to cut down or quit smoking, 2: I visit places that prohibit smoking, 3: for enjoyment or pleasure, 4: just tried it a few times, and 5: other $[5,15]$.

2.3. Sociodemographic Characteristics. Sociodemographic variables include age group (18-24, 25-44, 45-64, and $\geq 65$ years), sex, race (black, white, and other races), education level (<high school, high school or equivalent, and $>$ high school), employment status (employed, unemployed, student, retired, and unable to work), and annual household income $(<\$ 20,000, \$ 20,000-\$ 34,999, \quad \$ 35,000-\$ 49,999$, $\$ 50,000$, and no answer).
2.4. Smoking Status. Respondents who reported smoking $\geq$ 100 cigarettes during their lifetime and smoking every day or some days at the time of the survey were classified as current cigarette smokers. Those who reported smoking $\geq 100$ cigarettes during their lifetime but not smoking at the time of the survey were classified as former smokers. Respondents who reported smoking fewer than 100 cigarettes during their life time were classified as nonsmokers.

2.5. Statistical Analyses. Weighted prevalences and 95\% confidence intervals (CI) were calculated. E-cigarette use was compared across sociodemographic characteristics using chisquare tests and the associations between e-cigarette use and sociodemographic characteristics were examined using logistic regression adjusted for age, sex, race, education, employment, income, and conventional smoking. SAS version 9.4 (SAS Institute, Inc., Cary, North Carolina) was used to perform all statistical analyses accounting for the complex sample design; significance levels were determined based on a $p$ value less than 0.05 .

\section{Results and Discussion}

3.1. Results. The mean age was 46.8 years; one-third (33.5\%) were between the ages of 25 and 44 years; more than a third (35.3\%) were black; over half (52.1\%) were women and a similar proportion (51.4\%) reported having more than a high school education; more than half (57.1\%) reported being employed and about a quarter $(24.7 \%)$ had an annual household income of less than $\$ 20,000$ (Table 1).

In 2015, overall, 4.7\% (95\% CI 3.8-5.6) of Mississippi adults were current e-cigarette users, while one in five $(20.5 \%$, 95\% CI 18.7-22.2) reported that they had tried e-cigarettes at least once. The reported prevalence of having ever tried an e-cigarette was significantly higher among those who are $18-24$ years old $(33.9 \%, 95 \%$ CI $26.5-41.3, p<0.0001)$, whites $(23.0 \%, 95 \%$ CI 20.8-25.3, $p=0.0014)$, men $(24.4 \%$, 95\% CI 21.5-27.3, $p<0.0001$ ), students [as employment status] $(30.3 \%, 95 \%$ CI 20.3-40.2, $p<0.0001)$, those with an annual household income of less than $\$ 20,000(24.5 \%$, 95\% CI 20.7-28.3, $p=0.0418)$, and current smokers $(56.0 \%$, $95 \%$ CI $51.5-60.4, p<0.0001)$ than among their respective counterparts (Table 2). The prevalence of current e-cigarette use was significantly higher among young adults (18-24 years of age, $8.6 \%, 95 \%$ CI $4.5-12.7, p<0.0001)$, whites $(5.6 \%$, $95 \%$ CI $4.4-6.8, p=0.0190)$, men $(5.7 \%, 95 \%$ CI $4.2-7.3, p=$ $0.0367)$, those unable to work $(6.2 \%, 95 \%$ CI $3.7-8.8, p=$ $0.0019)$ those with an annual household income of $\$ 35,000-\$ 49,000(7.2 \%, 95 \%$ CI 3.9-10.5, $p=0.0376)$, and current smokers $(14.7 \%, 95 \%$ CI 11.6-17.8, $p<0.0001)$ than among their respective counterparts (Table 3 ).

Among Mississippi adults who had tried e-cigarettes at least once, more than half $(52.1 \%, 95 \%$ CI $47.2-57.0)$ and most (71.2\%, 95\% CI 62.1-80.3) of current e-cigarette users said that their main reason for using or trying e-cigarettes was "to cut down or quit smoking" (Figure 1). Only 7.1\% of nonsmokers reported having ever tried an e-cigarette (Table 3); among this group, one in five $(21.6 \%)$ said that the reason for trying or using e-cigarettes was "for enjoyment or pleasure" (Table 4). 
TABLE 1: Sociodemographic characteristics of Mississippi adults, Behavioral Risk Factor Surveillance System, 2015.

\begin{tabular}{|c|c|c|}
\hline Characteristic & $\%^{\mathrm{a}}(n=6,035)$ & $95 \% \mathrm{CI}$ \\
\hline \multicolumn{3}{|l|}{ Age, $y$} \\
\hline $18-24$ & 14.0 & $12.2-15.7$ \\
\hline $25-44$ & 33.5 & $31.6-35.3$ \\
\hline $45-64$ & 32.9 & $31.2-34.5$ \\
\hline$\geq 65$ & 19.7 & $18.6-20.7$ \\
\hline \multicolumn{3}{|l|}{ Race } \\
\hline Black & 37.1 & $35.3-38.9$ \\
\hline White & 59.6 & $57.7-61.4$ \\
\hline Other races & 3.3 & $2.5-4.2$ \\
\hline \multicolumn{3}{|l|}{ Sex } \\
\hline Male & 47.9 & $46.1-49.8$ \\
\hline Female & 52.1 & $50.2-53.9$ \\
\hline \multicolumn{3}{|l|}{ Education level } \\
\hline$<$ high school & 18.5 & $16.9-20.2$ \\
\hline High school or equivalent & 30.0 & $28.3-31.7$ \\
\hline >high school & 51.4 & $49.6-53.3$ \\
\hline \multicolumn{3}{|l|}{ Employment status } \\
\hline Employed & 57.1 & $55.1-59.1$ \\
\hline Unemployed & 15.0 & $13.5-16.6$ \\
\hline Student & 6.8 & $5.5-8.1$ \\
\hline Retired & 21.1 & $19.9-22.4$ \\
\hline Unable to work & 13.5 & $12.4-14.7$ \\
\hline \multicolumn{3}{|l|}{ Annual household income (\$) } \\
\hline$<20,000$ & 24.7 & $23.1-26.4$ \\
\hline $20,000-34,999$ & 22.0 & $20.4-23.6$ \\
\hline $35,000-49,999$ & 10.7 & $9.5-11.9$ \\
\hline$\geq 50,000$ & 26.7 & $25.1-28.3$ \\
\hline No answer & 15.9 & $14.5-17.3$ \\
\hline
\end{tabular}

CI, confidence interval; ${ }^{\mathrm{a}}$ weighted percent.

Among those aged 18-24 years, 17.1\% reported trying or using e-cigarettes "for enjoyment or pleasure" (Table 4).

Based on regression models adjusted for age, sex, race, education, employment status, income, and smoking status, Mississippi adults aged 18-24 years (adjusted odds ratio [AOR] 10.1, 95\% CI 3.4-29.6, $p<0.0001$ ), 25-44 years (AOR 3.4, 95\% CI 1.4-8.5, $p=0.0076$ ), and 45-64 years (AOR 3.1, 95\% CI 1.4-6.8, $p<0.0045$ ) have significantly higher odds of current e-cigarette use compared to adults 65 years and older (Table 5). The odds of current e-cigarette use were significantly higher among white adults (AOR 2.0, 95\% CI 1.2-3.4, $p=0.0127$ ) compared to black adults and significantly higher among current (AOR 15.2, 95\% CI 7.4-31.3, $p<0.0001)$ and former conventional cigarette smokers (AOR 3.5, 95\% CI 1.5-8.0, $p=0.0032$ ) compared to never smokers.

Similarly, the odds of ever tried an e-cigarette were significantly higher among Mississippi adults aged 18-24 years (AOR 15.9, 95\% CI 8.7-28.9, $p<0.0001$ ), 25-44 years (AOR 5.5, 95\% CI 3.6-8.6, $p<0.0001$ ), and 45-64 (AOR 3.3, 95\% CI 2.3-4.8, $p<0.0001$ ) years compared to adults
65 years and older. The odds of ever tried an e-cigarette were significantly higher among white adults (AOR 2.0, 95\% CI $1.5-2.8, p<0.0001$ ) compared to black adults, significantly higher among those with an annual household income of less than $\$ 20,000$ (AOR 1.6, 95\% CI 1.0-2.4, $p=0.0348$ ) compared to those with an annual household income of $\$ 50,000$ or more, and significantly higher among current (AOR 21.8, 95\% CI 14.9-31.6, $p<0.0001$ ) and former conventional cigarette smokers (AOR 4.1, 95\% CI 2.8-5.9, $p<0.0001)$ compared to never smokers (Table 5).

3.2. Discussion. To our knowledge, this is the first statewide study to assess e-cigarette use among adults in Mississippi. In 2015, 4.7\% of adult Mississippians were current e-cigarette users and $20.5 \%$ had ever tried an e-cigarette. This prevalence is higher than the national prevalence: among US adults, 3.7\% were current e-cigarette users and $12.6 \%$ had ever smoked an e-cigarette in 2014 [5]. The use of e-cigarettes differed significantly by age, race, gender, employment status, annual household income, and smoking status among Mississippi adults for both those who ever tried an e-cigarette and current e-cigarette users. When sociodemographic characteristics were controlled, current e-cigarette use was significantly associated with age, race, and smoking status among Mississippi adults. Similarly, ever tried an e-cigarette was significantly associated with age, race, income, and smoking status among Mississippi adults. This finding is consistent with previous studies $[2,5,15,16]$. A recent online survey of over 17,000 US adults indicated that they have been widely exposed to e-cigarette marketing through the media, and that such marketing targeted specific demographic groups $[4,17,18]$. The targeted marketing of e-cigarettes to specific subgroups may explain sociodemographic differences in e-cigarette use among Mississippi adults, especially young adults. A greater awareness of e-cigarettes due to television advertising [18] and social media [19] as well as a perception that they are less harmful than traditional cigarettes may have led to a higher prevalence of e-cigarette use among young adults [20]. In addition, low cost and ease of accessibility are potential contributors to e-cigarettes use [16]. In 2015, the prevalence of current conventional smoking was 23.0\% [12] among Mississippi adults; this prevalence is similar to the proportion of respondents who reported that they had ever tried an e-cigarette (20.5\%). Based on these observations, public health professionals, advocacy organizations, and policymakers should be concerned about ongoing conventional smoking prevention and cessation efforts in the state. Future assessments should examine the impact of the targeted marketing of e-cigarettes among subgroups, especially young adults and current conventional smokers in Mississippi.

The current use of e-cigarettes was highest among current smokers (14.7\%) and those aged 18-24 (8.6\%). The same two groups were most likely to have ever tried e-cigarettes: more than half $(56.0 \%)$ of current smokers and a third (33.9\%) of respondents aged 18-24 reported having tried an ecigarette at least once. In addition, $17.9 \%$ of former smokers, $7.1 \%$ of nonsmokers, and $30.3 \%$ of students reported having ever tried an e-cigarette. These findings highlight the need for e-cigarette policies in Mississippi, particularly policies 
TABLE 2: Ever tried an e-cigarette by sociodemographic characteristics among Mississippi adults, Behavioral Risk Factor Surveillance System, 2015 .

\begin{tabular}{|c|c|c|c|}
\hline \multirow{2}{*}{ Characteristic } & \multicolumn{3}{|c|}{ Ever tried an e-cigarette $^{\mathrm{b}}$} \\
\hline & $\%^{\mathrm{a}}(n=6,035)$ & $95 \% \mathrm{CI}$ & $p$ value $^{c}$ \\
\hline Overall & 20.5 & $18.7-22.2$ & \\
\hline \multicolumn{4}{|l|}{ Age, y } \\
\hline $18-24$ & 33.9 & $26.5-41.3$ & \multirow{4}{*}{$<0.0001$} \\
\hline $25-44$ & 26.3 & $22.8-29.7$ & \\
\hline $45-64$ & 19.1 & $16.7-21.5$ & \\
\hline$\geq 65$ & 5.1 & $3.9-6.3$ & \\
\hline \multicolumn{4}{|l|}{ Race } \\
\hline Black & 15.7 & $12.9-18.5$ & \multirow{3}{*}{0.0014} \\
\hline White & 23.0 & $20.8-25.3$ & \\
\hline Other races & 22.8 & $10.6-34.9$ & \\
\hline \multicolumn{4}{|l|}{ Sex } \\
\hline Male & 24.4 & $21.5-27.3$ & \multirow{2}{*}{$<0.0001$} \\
\hline Female & 17.0 & $14.9-19.0$ & \\
\hline \multicolumn{4}{|l|}{ Education level } \\
\hline$<$ high school & 21.3 & $16.6-26.1$ & \multirow{3}{*}{0.1714} \\
\hline High school or equivalent & 22.8 & $19.6-26.1$ & \\
\hline >high school & 18.9 & $16.7-21.1$ & \\
\hline \multicolumn{4}{|l|}{ Employment status } \\
\hline Employed & 22.9 & $20.3-25.6$ & \multirow{5}{*}{$<0.0001$} \\
\hline Unemployed & 26.8 & $21.2-32.5$ & \\
\hline Student & 30.3 & $20.3-40.2$ & \\
\hline Retired & 7.2 & $5.5-9.0$ & \\
\hline Unable to work & 19.9 & $16.0-23.8$ & \\
\hline \multicolumn{4}{|l|}{ Annual household income (\$) } \\
\hline$<20,000$ & 24.5 & $20.7-28.3$ & \multirow{5}{*}{0.0418} \\
\hline $20,000-34,999$ & 21.3 & $17.5-25.1$ & \\
\hline $35,000-49,999$ & 20.6 & $15.6-25.7$ & \\
\hline$\geq 50,000$ & 17.1 & $14.0-20.1$ & \\
\hline No answer & 18.6 & $14.2-23.1$ & \\
\hline \multicolumn{4}{|l|}{ Smoking status } \\
\hline Current & 56.0 & $51.5-60.4$ & \multirow{3}{*}{$<0.0001$} \\
\hline Former & 17.9 & $14.3-21.4$ & \\
\hline Never & 7.1 & $5.6-8.7$ & \\
\hline
\end{tabular}

CI, confidence interval; ${ }^{a}$ weighted percent; ${ }^{b}$ ever tried an e-cigarette were respondents who answered "yes" to "Have you ever tried an e-cigarette, even just one time in your entire life?"; ' determined by $X^{2}$ test.

focused on preventing young adults and nonsmokers from initiating e-cigarette use to preserve the previous gains in smoking prevention. Policy guidance on e-cigarettes from the American Heart Association promotes the inclusion of ecigarettes in smoke-free laws, in state regulations that prohibit the sale of e-cigarettes to minors, and in laws that restrict the marketing and advertising of e-cigarettes to minors, as well as monitoring e-cigarettes use and taxation [3]. A recent national study reported an increase in e-cigarettes sales, from 2011 to 2015 [21]. Currently, Mississippi does not levy a tax on e-cigarettes [22]. While there are 124 smoke-free cities and towns in Mississippi, only 79 of these have ordinances that include restrictions on e-cigarettes [22].
Unregulated e-cigarette use has the potential to erode gains in conventional smoking cessation and smoke-free laws [3]. Evidence suggests that increasing retail prices and taxing ecigarettes could lead to a reduction in sales [23].

Notably, two-thirds $(66.8 \%)$ of current conventional cigarettes smokers who have ever tried e-cigarettes and most $(82.5 \%)$ of current conventional cigarettes smokers who are current e-cigarette users reported that their main reason for using e-cigarettes was "to cut down or quit smoking". However, the evidence on the use of e-cigarettes as a cessation aid is unclear [8]. Future studies should assess the efficacy of e-cigarettes as a smoking cessation aid or smoking substitute to prevent relapse among Mississippi smokers. 
TABLE 3: Current e-cigarette use among Mississippi adults by sociodemographic characteristics, Behavioral Risk Factor Surveillance System, 2015.

\begin{tabular}{|c|c|c|c|}
\hline \multirow{2}{*}{ Characteristic } & \multicolumn{3}{|c|}{ Current e-cigarette users ${ }^{\mathrm{b}}$} \\
\hline & $\%^{\mathrm{a}}(n=6,035)$ & $95 \% \mathrm{CI}$ & $p$ value $^{c}$ \\
\hline Overall & 4.7 & $3.8-5.6$ & \\
\hline \multicolumn{4}{|l|}{ Age, y } \\
\hline $18-24$ & 8.6 & $4.5-12.7$ & \multirow{4}{*}{$<0.0001$} \\
\hline $25-44$ & 5.5 & $3.7-7.2$ & \\
\hline $45-64$ & 4.9 & $3.6-6.1$ & \\
\hline$\geq 65$ & 0.9 & $0.4-1.4$ & \\
\hline \multicolumn{4}{|l|}{ Race } \\
\hline Black & 2.9 & $1.6-4.3$ & \multirow{3}{*}{0.0190} \\
\hline White & 5.6 & $4.4-6.8$ & \\
\hline Other races & 8.1 & $0.8-15.3$ & \\
\hline \multicolumn{4}{|l|}{ Sex } \\
\hline Male & 5.7 & $4.2-7.3$ & \multirow{2}{*}{0.0367} \\
\hline Female & 3.8 & $2.8-4.8$ & \\
\hline \multicolumn{4}{|l|}{ Education level } \\
\hline$<$ high school & 4.4 & $2.4-6.5$ & \multirow{3}{*}{0.1171} \\
\hline High school or equivalent & 6.2 & $4.2-8.2$ & \\
\hline >high school & 4.0 & $2.9-5.1$ & \\
\hline \multicolumn{4}{|l|}{ Employment status } \\
\hline Employed & 5.5 & $4.0-6.9$ & \multirow{5}{*}{0.0019} \\
\hline Unemployed & 6.0 & $3.1-8.9$ & \\
\hline Student & 3.7 & $0.1-7.3$ & \\
\hline Retired & 1.2 & $0.6-1.9$ & \\
\hline Unable to work & 6.2 & $3.7-8.8$ & \\
\hline \multicolumn{4}{|l|}{ Annual household income (\$) } \\
\hline$<20,000$ & 6.2 & $4.1-8.3$ & \multirow{5}{*}{0.0376} \\
\hline $20,000-34,999$ & 4.4 & $2.6-6.3$ & \\
\hline $35,000-49,999$ & 7.2 & $3.9-10.5$ & \\
\hline$\geq 50,000$ & 3.6 & $2.0-5.2$ & \\
\hline No answer & 2.9 & $1.3-4.5$ & \\
\hline \multicolumn{4}{|l|}{ Smoking status } \\
\hline Current & 14.7 & $11.6-17.8$ & \multirow{3}{*}{$<0.0001$} \\
\hline Former & 3.3 & $1.6-4.9$ & \\
\hline Never & 1.1 & $0.4-1.8$ & \\
\hline
\end{tabular}

$\mathrm{CI}$, confidence interval; " weighted percent; ${ }^{\mathrm{b}}$ current users were respondents who reported ever trying an e-cigarette and answered "every day or some days" to "Do you now smoke e-cigarettes every day, some days, or not at all?"; ' determined by $X^{2}$ test.

The most significant health issue related to e-cigarettes is whether or not e-cigarette use reduces the overall tobaccoassociated health risk $[3,24]$. Given the limited evidence on the health effects of e-cigarettes [9], there is a need for continual monitoring of e-cigarette use in Mississippi to assess awareness, prevalence, disparities, possible health effects and health promotion, and prevention strategies to reduce their use.

These findings have three main potential limitations. First, BRFSS consists of self-reported information on ecigarette use, which is subject to recall bias and social desirability bias [25]; however, past studies have validated self-reported smoking data [26]. Second, because the ecigarette module was only included in the Mississippi BRFSS in 2015, we could not assess trends in e-cigarette use over time [10]. Third, because the data are cross-sectional, we cannot make causal inferences based on the results. Finally, Mississippi BRFSS data include only adults (18 years and older); therefore, the findings may not be generalizable to younger populations. Key strengths of the current study include the use of a representative sample of the Mississippi adult population.

\section{Conclusions}

In 2015, about 5\% of Mississippi adults were current ecigarette users and one in five adults reported having ever 
TABLe 4: Reasons for trying or using e-cigarettes among Mississippi adults who have ever tried e-cigarettes by select demographic characteristics, Behavioral Risk Factor Surveillance System, 2015.

\begin{tabular}{|c|c|c|c|c|}
\hline \multirow{2}{*}{ Characteristic } & \multicolumn{2}{|c|}{ To try to quit smoking } & \multicolumn{2}{|c|}{ For enjoyment or pleasure } \\
\hline & $\%^{\mathrm{a}}(n=6,035)$ & $95 \% \mathrm{CI}$ & $\%^{\mathrm{a}}(n=6,035)$ & $95 \% \mathrm{CI}$ \\
\hline Overall & 52.1 & $47.2-57.0$ & 4.9 & $2.6-7.1$ \\
\hline \multicolumn{5}{|l|}{ Age (years) } \\
\hline $18-24$ & 34.4 & $21.1-47.8$ & 17.1 & $7.8-26.5$ \\
\hline $25-44$ & 49.2 & $41.4-57.0$ & 2.2 & $0.3-4.1$ \\
\hline $45-64$ & 65.7 & $59.0-72.4$ & 0.8 & $0.1-1.5$ \\
\hline$\geq 65$ & 65.6 & $54.4-76.7$ & 1.1 & $0.0-2.5$ \\
\hline \multicolumn{5}{|l|}{ Race } \\
\hline Black & 49.4 & $39.5-59.3$ & 6.8 & $1.8-11.9$ \\
\hline White & 52.4 & $46.7-58.2$ & 3.9 & $1.5-6.3$ \\
\hline Other races & 65.8 & $36.0-95.5$ & 10.4 & $0.0-26.9$ \\
\hline \multicolumn{5}{|l|}{ Sex } \\
\hline Male & 45.9 & $38.9-52.8$ & 4.9 & $1.7-8.2$ \\
\hline Female & 60.0 & $53.5-66.5$ & 4.8 & $1.9-7.7$ \\
\hline \multicolumn{5}{|l|}{ Smoking status } \\
\hline Current & 66.8 & $61.0-72.6$ & 0.5 & $0.0-0.9$ \\
\hline Former & 49.9 & $38.6-61.2$ & 1.9 & $0.0-4.9$ \\
\hline Never & 8.2 & $3.0-13.3$ & 21.6 & $11.7-31.6$ \\
\hline
\end{tabular}

CI, confidence interval; ${ }^{a}$ weighted percent.

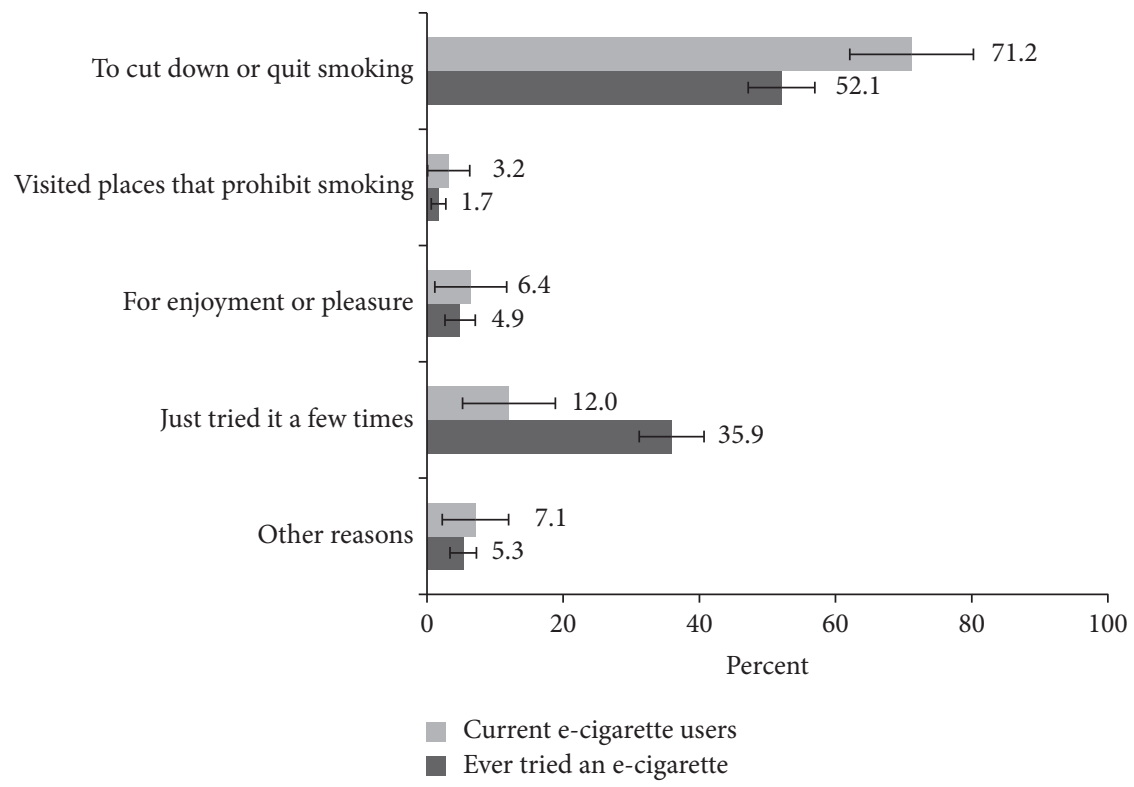

FIGURE 1: Reasons for trying or using e-cigarettes among Mississippi adults who have ever tried e-cigarettes and current e-cigarette users, Behavioral Risk Factor Surveillance System, 2015.

tried an e-cigarette. E-cigarette use among adults differed by sociodemographic characteristics and by smoking status. E-cigarette use is associated with age, race, income, and smoking status among Mississippi adults. Most current ecigarette users and more than half of those who have ever tried e-cigarettes reported that a main reason for trying or using e-cigarettes was "to cut down or quit smoking." These findings highlight the need for e-cigarette policies and community interventions addressing the initiation of ecigarette use among at-risk subgroups in Mississippi. 
TABLE 5: Odds of current e-cigarette use and ever tried an e-cigarette among Mississippi adults by sociodemographic characteristics, Behavioral Risk Factor Surveillance System, 2015.

\begin{tabular}{|c|c|c|c|c|c|c|}
\hline \multirow{2}{*}{ Characteristic } & \multicolumn{3}{|c|}{ Current e-cigarette users ${ }^{\mathrm{a}}$} & \multicolumn{3}{|c|}{ Ever tried an e-cigarette $^{\mathrm{b}}$} \\
\hline & $\mathrm{AOR}^{\mathrm{c}}$ & $95 \% \mathrm{CI}$ & $p$ value & $\mathrm{AOR}$ & $95 \% \mathrm{CI}$ & $p$ value \\
\hline \multicolumn{7}{|l|}{ Age (years) } \\
\hline $18-24$ & 10.1 & $3.4-29.6$ & $<0.0001$ & 15.9 & $8.7-28.9$ & $<0.0001$ \\
\hline $25-44$ & 3.4 & $1.4-8.5$ & 0.0076 & 5.5 & $3.6-8.6$ & $<0.0001$ \\
\hline $45-64$ & 3.1 & $1.4-6.8$ & 0.0045 & 3.3 & $2.3-4.8$ & $<0.0001$ \\
\hline$\geq 65$ & 1.0 & Referent & & 1.0 & Referent & \\
\hline \multicolumn{7}{|l|}{ Race } \\
\hline White & 2.0 & $1.2-3.4$ & 0.0127 & 2.0 & $1.5-2.8$ & $<0.0001$ \\
\hline Black & 1.0 & Referent & & 1.0 & Referent & \\
\hline Other races & 2.5 & $0.6-9.5$ & 0.1907 & 1.2 & $0.5-3.1$ & 0.6497 \\
\hline \multicolumn{7}{|l|}{ Sex } \\
\hline Female & 1.0 & Referent & & 1.0 & Referent & \\
\hline Male & 1.2 & $0.8-1.9$ & 0.3831 & 1.2 & $0.9-1.6$ & 0.1126 \\
\hline \multicolumn{7}{|l|}{ Education level } \\
\hline$<$ high school & 0.7 & $0.4-1.4$ & 0.3413 & 0.8 & $0.5-1.2$ & 0.2609 \\
\hline High school or equivalent & 1.2 & $0.7-1.9$ & 0.5919 & 1.0 & $0.8-1.4$ & 0.8139 \\
\hline$>$ high school & 1.0 & Referent & & 1.0 & Referent & \\
\hline \multicolumn{7}{|l|}{ Employment status } \\
\hline Employed & 1.0 & Referent & & 1.0 & Referent & \\
\hline Unemployed & 0.7 & $0.4-1.4$ & 0.3761 & 0.9 & $0.6-1.4$ & 0.6852 \\
\hline Student & 0.6 & $0.2-1.8$ & 0.3462 & 1.3 & $0.7-2.6$ & 0.4707 \\
\hline Retired & 0.7 & $0.3-1.5$ & 0.3356 & 0.8 & $0.5-1.2$ & 0.2767 \\
\hline Unable to work & 1.3 & $0.7-2.3$ & 0.4479 & 0.8 & $0.5-1.2$ & 0.2196 \\
\hline \multicolumn{7}{|l|}{ Annual household income (\$) } \\
\hline$<20,000$ & 1.5 & $0.7-3.1$ & 0.3033 & 1.6 & $1.0-2.4$ & 0.0348 \\
\hline $20,000-34,999$ & 1.0 & $0.5-2.1$ & 0.9369 & 1.2 & $0.8-1.8$ & 0.383 \\
\hline $35,000-49,999$ & 1.8 & $0.8-3.8$ & 0.1298 & 1.1 & $0.7-1.7$ & 0.7367 \\
\hline$\geq 50,000$ & 1.0 & Referent & & 1.0 & Referent & \\
\hline No answer & 0.8 & $0.4-1.9$ & 0.639 & 1.3 & $0.8-2.1$ & 0.3258 \\
\hline \multicolumn{7}{|l|}{ Smoking status } \\
\hline Current & 15.2 & $7.4-31.3$ & $<0.0001$ & 21.8 & $14.9-31.6$ & $<0.0001$ \\
\hline Former & 3.5 & $1.5-8.0$ & 0.0032 & 4.1 & $2.8-5.9$ & $<0.0001$ \\
\hline Never & 1.0 & Referent & & 1.0 & Referent & \\
\hline
\end{tabular}

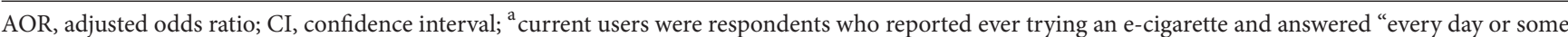
days" to "Do you now smoke e-cigarettes every day, some days, or not at all?"; " ever tried an e-cigarette were respondents who answered "yes" to "Have you ever tried an e-cigarette, even just one time in your entire life?"; ' adjusted for age, sex, race, education, employment status, income, and smoking status.

\section{Conflicts of Interest}

The authors declare that they have no conflicts of interest.

\section{Acknowledgments}

The authors sincerely thank Cassandra Dove, Dr. Victor Sutton, Ron McAnally, and Dr. Mary Currier of the Mississippi State Department of Health and Dr. Fleetwood Loustalot of the Division for Heart Disease and Stroke Prevention, Centers for Disease Control and Prevention. This work was supported by The Mississippi Office of Tobacco Control, CDC (Grant no. 5U50DP003088-04) and the National Institute on Minority Health and Health Disparities of the National Institutes of Health under Award no. P20MD006899.

\section{References}

[1] Food and Drug Administration (FDA), Evaluation of ECigarettes, 2009, http://www.fda.gov/downloads/Drugs/ScienceResearch/ucm173250.pdf.

[2] G. Syamlal, A. Jamal, B. A. King, and J. M. Mazurek, "Electronic cigarette use among working adults - United States, 2014," Morbidity and Mortality Weekly Report, vol. 65, no. 22, pp. 557561, 2016. 
[3] A. Bhatnagar, L. P. Whitsel, K. M. Ribisl et al., "Electronic cigarettes: A policy statement from the American Heart Association," Circulation, vol. 130, no. 16, pp. 1418-1436, 2014.

[4] R. A. Grana and P. M. Ling, “"Smoking revolution”: A content analysis of electronic cigarette retail websites," American Journal of Preventive Medicine, vol. 46, no. 4, pp. 395-403, 2014.

[5] C. A. Schoenborn and R. M. Gindi, "Electronic cigarette use among adults: United States, 2014," NCHS Data Brief, vol. 217, pp. 1-8, 2015.

[6] J.-F. Etter, C. Bullen, A. D. Flouris, M. Laugesen, and T. Eissenberg, "Electronic nicotine delivery systems: A research agenda," Tobacco Control, vol. 20, no. 3, pp. 243-248, 2011.

[7] K. A. Vickerman, K. M. Carpenter, T. Altman, C. M. Nash, and S. M. Zbikowski, "Use of electronic cigarettes among state tobacco cessation quitline callers," Nicotine and Tobacco Research, vol. 15, no. 10, pp. 1787-1791, 2013.

[8] M. Malas, J. van der Tempel, R. Schwartz et al., "Electronic cigarettes for smoking cessation: A systematic review," Nicotine and Tobacco Research, vol. 18, no. 10, pp. 1926-1936, 2016.

[9] U.S. Department of Health and Human Services, "E-Cigarette Use Among Youth and Young Adults. A Report of the Surgeon General," Atlanta, GA: U.S. Department of Health and Human Services, Centers for Disease Control and Prevention, National Center for Chronic Disease Prevention and Health Promotion, Office on Smoking and Health, 2016. Centers for Disease Control and Prevention.

[10] B. A. King, S. Alam, G. Promoff, R. Arrazola, and S. R. Dube, "Awareness and ever-use of electronic cigarettes among U.S. adults, 2010-2011," Nicotine and Tobacco Research, vol. 15, no. 9, pp. 1623-1627, 2013.

[11] Electronic Cigarettes Use in Utah, 2016, http://www.tobaccofreeutah.org/pdfs/DataBrief_ECigarettesfinal.pdf.

[12] Centers for Disease Control and Prevention, National Center for Chronic Disease Prevention and Health Promotion, Division of Population Health. BRFSS Prevalence \& Trends Data. 2015. http://wwwdev.cdc.gov/brfss/brfssprevalence/.

[13] C. Pierannunzi, S. S. Hu, and L. Balluz, "A systematic review of publications assessing reliability and validity of the Behavioral Risk Factor Surveillance System (BRFSS), 2004-2011," BMC Medical Research Methodology, vol. 13, article 49, 2013.

[14] "Methodologic changes in the Behavioral Risk Factor Surveillance System in 2011 and potential effects on prevalence estimates," Morbidity and Mortality Weekly Report, vol. 61, no. 22, pp. 410-413, 2012.

[15] L. Schmidt, A. Reidmohr, T. S. Harwell, and S. D. Helgerson, "Prevalence and reasons for initiating use of electronic cigarettes among adults in montana, 2013," Preventing Chronic Disease, vol. 11, no. 11, Article ID 140283, 2014.

[16] K. W. Bold, G. Kong, D. A. Cavallo, D. R. Camenga, and S. Krishnan-Sarin, "Reasons for trying e-cigarettes and risk of continued use," Pediatrics, vol. 138, no. 3, Article ID e20160895, 2016.

[17] S. L. Emery, L. Vera, J. Huang, and G. Szczypka, "Wanna know about vaping? Patterns of message exposure, seeking and sharing information about e-cigarettes across media platforms," Tobacco Control, vol. 23, pp. iiil-iii25, 2014.

[18] J. C. Duke, Y. O. Lee, A. E. Kim et al., "Exposure to electronic cigarette television advertisements among youth and young adults," Pediatrics, vol. 134, no. 1, pp. e29-e36, 2014.

[19] J. Huang, J. Tauras, and F. J. Chaloupka, "The impact of price and tobacco control policies on the demand for electronic nicotine delivery systems," Tobacco Control, vol. 23, pp. iii41-iii47, 2014.
[20] A. S. L. Tan and C. A. Bigman, "E-cigarette awareness and perceived harmfulness: Prevalence and associations with smokingcessation outcomes," American Journal of Preventive Medicine, vol. 47, no. 2, pp. 141-149, 2014.

[21] K. L. Marynak, D. G. Gammon, B. A. King et al., "National and State Trends in Sales of Cigarettes and E-Cigarettes, U.S., 2011-2015," American Journal of Preventive Medicine, vol. 53, no. 1, pp. 96-101, 2017.

[22] The health \& Economic burden of tobacco on Mississippi. http://mstobaccodata.org/wp-content/uploads/2015/08/mtdtobacco-report.pdf.

[23] J. Huang, R. Kornfield, G. Szczypka, and S. L. Emery, "A crosssectional examination of marketing of electronic cigarettes on Twitter," Tobacco Control, vol. 23, pp. iii26-iii30, 2014.

[24] K. E. Farsalinos and R. Polosa, "Safety evaluation and risk assessment of electronic cigarettes as tobacco cigarette substitutes: A systematic review," Therapeutic Advances in Drug Safety, vol. 5, no. 2, pp. 67-86, 2014.

[25] D. K. Hayes, A. Z. Fan, R. A. Smith, and J. M. Bombard, "Trends in selected chronic conditions and behavioral risk factors among women of reproductive age, Behavioral Risk Factor Surveillance System, 2001-2009," Preventing Chronic Disease, vol. 8, no. 6, article no. A120, 2011.

[26] R. S. Caraballo, G. A. Giovino, and T. F. Pechacek, "Self-reported cigarette smoking vs. serum cotinine among U.S. adolescents," Nicotine and Tobacco Research, vol. 6, no. 1, pp. 19-25, 2004. 


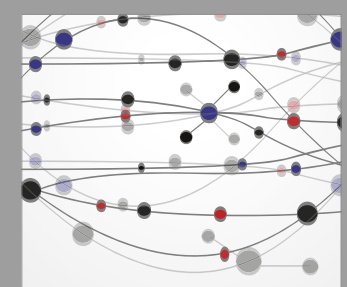

The Scientific World Journal
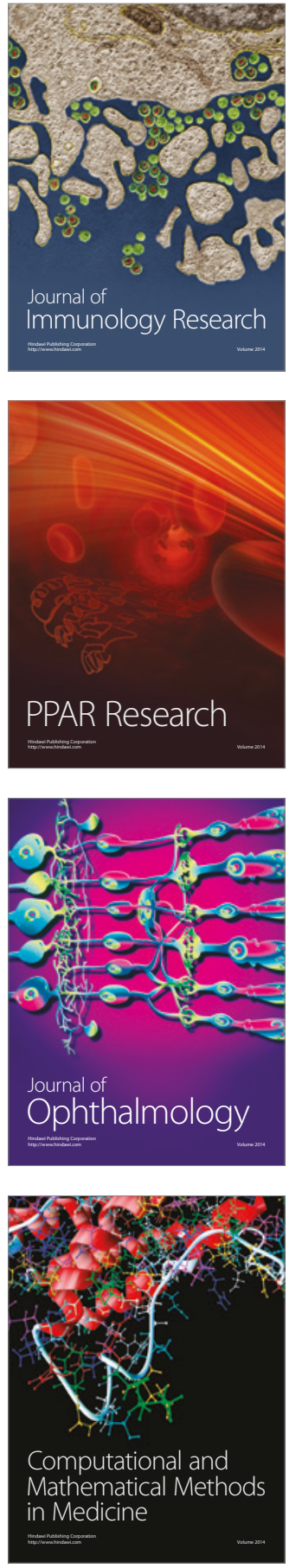

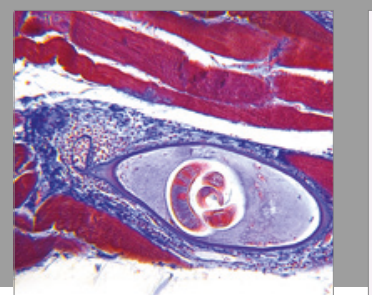

Gastroenterology Research and Practice
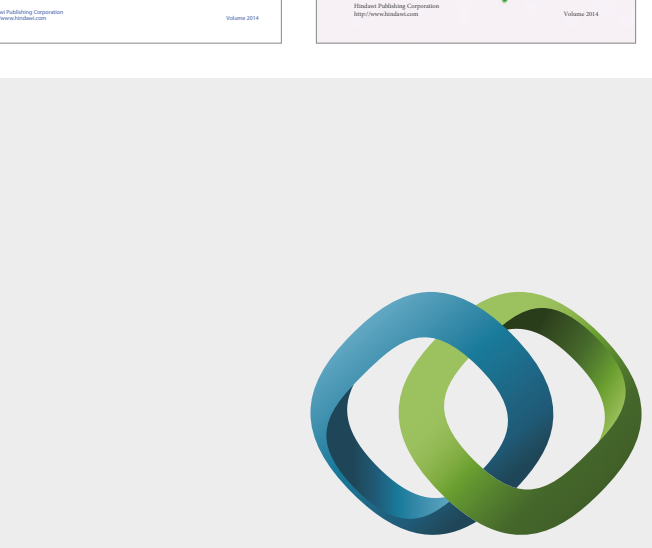

\section{Hindawi}

Submit your manuscripts at

https://www.hindawi.com
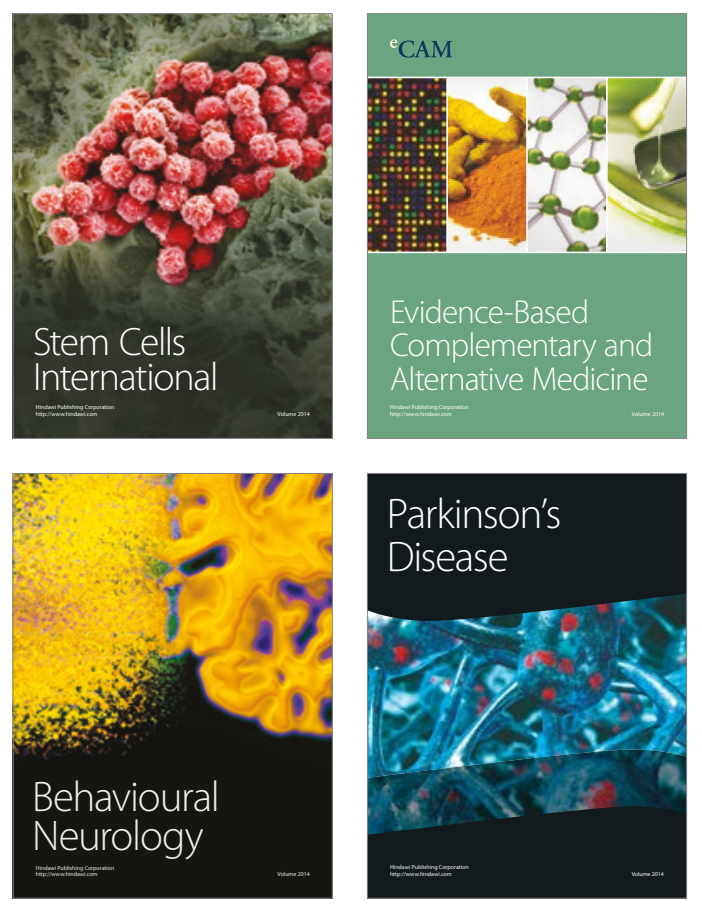
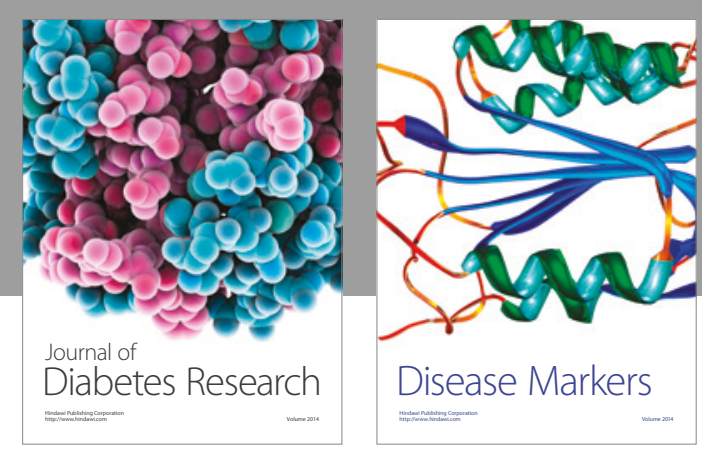

Disease Markers
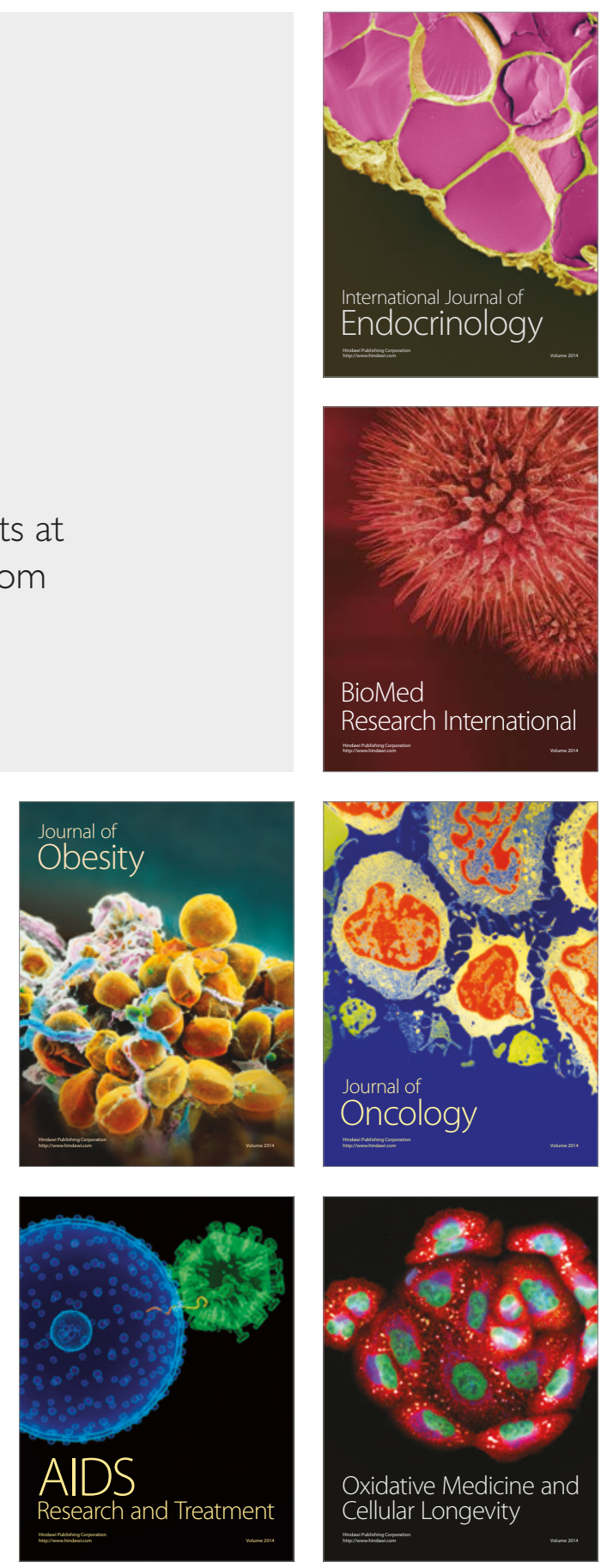